\title{
Design of Dissipative Braces for an Existing Strategic Building with a Pushover Based Procedure
}

\author{
Alessandro Vittorio Bergami and Camillo Nuti \\ Department of Architecture, University of Roma Tre, Rome 00153, Italy
}

\begin{abstract}
The research presented in this paper deals with the seismic protection of existing frame structures by means of passive energy dissipation. An iterative displacement-based procedure, based on capacity spectrum, to design dissipative bracings for seismic retrofitting of the frame structures is described, and some applications are discussed. The procedure can be used with any typology of dissipative device and for different performance targets. In this work, the procedure has been applied, with both traditional pushover (load profile proportional to first mode) and multimodal pushover, to an existing RC (reinforced concrete) frame building. In the application, the buckling restrained braces have been used in order to prevent damages to both the structure and non structural elements. The use of multimodal pushover proves to be more effective than pushover based on single mode in case of medium rise RC frame building (higher than $30 \mathrm{~m}$ ) but, once this building is retrofitted, and therefore regularized, with a bracing system, the difference between using monomodal or multimodal pushover becomes insignificant.
\end{abstract}

Key words: Dissipative braces, earthquake engineering, energy dissipation, seismic retrofitting.

\section{Introduction}

The use of dissipative bracings, though it seems conceptually clear and simple, requires a more complex design procedure than other retrofitting methods like base isolation. The greater complexity derives from the non linear behaviour of the dissipative devices and therefore of the final retrofitted structure. Despite that, during the last years, many design procedure has been published and, those based on the capacity spectrum method are the most useful for practical. In fact with this approach nonlinear dynamic analyses can be skipped in favour of static nonlinear analyses that are simpler to be managed. Otherwise, also within those procedures, many have a theoretical approach that can be difficulty associated with a widespread professional use. In fact, frequently, the characteristics of an existing building (e.g., irregular distribution of masses and stiffness, presence of a soft story) can compromise the effectiveness of procedures that

Corresponding author: Alessandro Vittorio Bergami, Ph.D., research fields: earthquake engineering and structural engineering. E-mail: alessandro.bergami@uniroma3.it. impose a predefined loading pattern during pushover analyses. As discussed in Bergami and Nuti $[1,2]$, the design of dissipative devices has two main goals: to improve dissipation and regularize strength end stiffness distribution by (this can be done adopting an adequate criteria to distribute the braces along the elevation and inside the plan of the building). Moreover, in case of medium rise building (quite widespread in Italy), it is a matter of fact that the relevance of higher modes not only depends on their level of irregularity but it is also related to the quite high number of stories. To check such hypothesis, the design procedure has been tested on a medium rise irregular existing building. The necessity of using a multi-modal pushover [3] instead of the standard single mode pushover procedure has been investigated by performing multi-modal pushover and non-linear dynamic analysis on both the existing and retrofitted building.

\section{Dissipative Bracings Positioning: Structural Effects}

The insertion of dissipative braces into the structural 
frame involves significant effects that can be grouped in two categories: effects on structural response and effects on the architecture of the building. Concerning the former, the braces increase both stiffness and strength, as usually happens, consequently both modal shapes and the capacity curve of the structure are modified. Moreover, for a given top displacement, these improve damping and, therefore, reduce demand. In this respect, stiffness increase could render less efficient, or even useless, the increase of dissipation. Therefore, a careful mix of stiffness and dissipation is requested. This subject is discussed in the following.

The bracing system has to be compatible with the architecture of the building: therefore spatial distribution of the braces descents from a compromise between the optimization of the dissipative system and the functionality of the building.

Although braces distribution should be analyzed case by case, some general considerations can be made: braces should reduce or eliminate eventual translation-rotation coupling effects, induce constant interstorey drifts, maximize damping for a given top displacement and exclude soft storey behavior. The additional stiffness offered by the braces, if well distribute, will increase storey stiffness proportionally to interstorey drifts that are higher in correspondence to soft storey (e.g., where is a reduction of columns cross section, localized lack of the infills: therefore if there are soft storey because of the absence of infills): therefore storey mechanism can be avoided in favour of global and more dissipative mechanisms.

Different criteria to distribute the additional stiffness are proposed in scientific literature: constant at each story, proportional to story shear, proportional to interstorey drifts of the original structure. In this work, the latter is assumed and therefore, given the interstorey drift $\delta_{j}$, the stiffness $K_{b, j}^{\prime}$ corresponding to each storey of the bracing system is:

$$
K_{b, j}^{\prime}=K_{\text {global }} c_{b, j}
$$

where:

$$
c_{b j}=\frac{\delta_{j}}{\max _{j}\left\{\delta_{j}\right\}}
$$

Each brace is a composite element realized coupling an elastic element (usually a steel profile) with a dissipative device in series. The latter will determines the desired yielding force whereas the former will be designed to assure the desired stiffness of the series.

\section{Evaluation of the Equivalent Viscous Damping}

To each step during the deformation of the structure, a specific amount of energy is dissipated by both the structure, be it with or without dissipative braces, and of course by the braces.

This dissipated energy can be expressed in terms of equivalent viscous damping that can be evaluated according to the formula proposed by Chopra and Goel [3]: the equivalent viscous damping of the structure $v_{e q, S}$ at the generic displacement $D$ is:

$$
v_{e q, S}=\frac{1}{4 \pi} \frac{E_{D, S}}{E_{S, S}}
$$

All the parameters of the Eq. (3) can be easily determined from the capacity curve: $E_{D, S}$ is the energy dissipated in a single cycle of amplitude $D$ and $E_{S, S}$ is the elastic strain energy corresponding to the displacement $D$. Referring to an equivalent bilinear capacity curve (it can be determined from the capacity curve using one of the methods available in literature) in terms of Eq. (3), considering an ideal elasto-plastic hysteretic cycle, can be determined as follow:

$$
\begin{gathered}
E_{D, S}^{\text {bilinear }}=4\left(F_{s y} D-D_{s y} F_{s}(D)\right) \\
E_{S, S}=\frac{1}{2} D F_{s}(D)
\end{gathered}
$$

where,

$D$ is the displacement reached from the structure;

$F_{s}(D)$ is the force corresponding to $D$ (the force is the base shear);

$D_{s y}$ is the yield displacement;

$F_{s y}$ is the yield force.

It is well known that the hysteretic cycle of a real structure differs from the ideal cycle, therefore this difference can be taken into account adopting a corrective coefficient $C_{S}$ for the structure and $C_{B}$ for the 
braces ( $C=1$ for the ideal elasto-plastic behaviour). Therefore:

$$
\begin{gathered}
E_{D, S}=\chi_{S} E_{D, S}^{\text {bilinear }} \\
E_{D, B}=\chi_{B} E_{D, B}^{\text {bilinear }}
\end{gathered}
$$

where, $E_{D, B}^{\text {bilinear }}$ is the energy dissipated by the ideal hysteretic cycle of the dissipative brace.

For the applications discussed in this paper, the parameter $C_{S}$ has been determined referring to the provisions of ATC40 [4]. For the braces, the assumption of $C_{B} \approx 1$ has been considered reasonable: in fact, according to AISC/SEAOC-Recommended Provisions for Buckling-Restrained Braced Frames [5], the force-displacement relationship of a BRB (buckling restrained brace) can be idealized as a bilinear curve. However, different evaluations for $C_{S}$ and $C_{B}$ can be adopted (e.g., according to experimental tests or guidelines), if the case, with no difference in the procedure. The authors have assumed a bilinear curve characterized by a yielding force equal to the yielding traction force (the maximum compressive strength of BRBs is slightly larger than the maximum tensile strength due to the confining effect of the external tube): the hysteretic cycle obtained is elasto-plastic but precautionary smaller than the real one. Then the evaluation of the equivalent viscous damping of the braced structure $v_{e q, S+B}$, to be added to the inherent damping $v_{I}$ (usually $v_{I}=5 \%$ for RC (reinforced concrete) structures and $v_{I}=2 \%$ for steel ones), can be obtained using the following expression:

$$
v_{e q, S+B}=\frac{1}{4 \pi} \frac{E_{D, S+B}}{E_{S, S+B}}=\frac{1}{4 \pi}\left[\frac{\chi_{S} E_{D, S}^{\text {bilinear }}}{E_{S, S+B}}+\frac{\chi_{B} \sum_{j} E_{D, B, j}^{\text {bilinear }}}{E_{S, S+B}}\right]
$$

$v_{e q, S}=\chi_{S} \frac{1}{4 \pi} \frac{E_{D, S}^{\text {bilinear }}}{E_{S, S+B}} ; v_{e q, B}=\chi_{B} \frac{1}{4 \pi} \frac{\sum_{j} E_{D, B, j}^{\text {bilinear }}}{E_{S, S+B}}(9)$ where, $E_{D, B, j}^{\text {bilinear }}$ is the energy dissipated by the dissipative braces placed at level $j$.

Eq. (8) can be generalized assuming that
$E_{D, B, j}^{\text {bilinear }}=\sum_{i} E_{D, B, i}^{\text {bilinar }}$ with $E_{D, B, i}^{\text {bilinear }}$ the energy dissipated by the $i$ braces placed at level $j$. Note that $v_{e q, S}$ and $v_{e q, B}$ are obtained dividing the dissipated energy, determined from the capacity curve of $S$ or $B$, respectively, by the elastic strain energy of the braced structure, determined from the curve of $S+B$.

\section{The Design Procedure: Main Steps}

The design procedure can be applied using every typology of pushover because it requires the only definition of capacity curve and interstorey drift distribution. Therefore, the use of the multimodal procedure does not modify the proposed procedure that can be summarized in the following steps:

(1) Define the seismic action: The seismic action is defined in terms of elastic response acceleration spectrum $\left(T-S_{a}\right)$;

(2) Select the target displacement: The target displacement is selected (for example the top displacement $D_{t}{ }^{*}$ ) according to the performance desired (limit state);

(3) Define the capacity curve: The capacity curve of the braced structure $S+B$, in terms of top displacement and base shear $\left(D_{t}-V_{b}\right)$, is determined by pushover analysis. The pushover analysis can be easily performed using a software for structural analysis: many different force distributions can be adopted selecting the best option for the specific case (e.g., modal shape load profile).

If a modal shape load profile has been selected, it is important to underline that the modal shape is influenced by the bracing system and consequently, at each iteration, the load profile has to be updated to the modal shape of the current braced structure.

Notice that, at the first iteration, the structure without braces is considered and therefore the capacity curve obtained will be fundamental for the evaluation of the contribution offered by the existing structure to the braced structure of the subsequent iterations;

(4) Define the equivalent bilinear capacity curve 
(Fig. 1): The capacity curve is approximated by a simpler bilinear curve $D_{t}-F_{s+b}$ that is completely defined by the yielding point $\left(D_{s+b, y}, F_{s+b, y}\right)$ and the hardening ratio $\beta_{s+b}$ (at the first iteration the parameters correspond to $D_{s, y}, F_{s, y}, \beta_{s}$ of the existing building);

(5) Define equivalent single degree of freedom: The MDOF (multi degree of freedom) system is converted in a SDOF (single degree of freedom) system by transforming the capacity curve into the capacity $\operatorname{spectrum}\left(S_{d t}-S_{a b}\right)$.

$$
S_{d t}=\frac{D_{t}}{\Gamma \phi_{t}} ; S_{a}=\frac{F_{S+B}}{\Gamma \cdot L}
$$

where, $\Gamma$ is the participation factor of the modal shape $\phi$ $\left(\Gamma=\left(\phi^{T} M I\right) /\left(\phi^{T} M \phi\right)\right)$ and $L=\phi^{T} M I$.

The modal characteristics of the braced structure may change at each iteration due to new brace characteristics. Therefore, $\phi, \Gamma$ and $L$ have to be updated with the current configuration;

(6) Evaluate the required equivalent viscous damping (Fig. 2): The equivalent viscous damping $v_{e q, S+B}^{*}$ of the braced structure at the displacement of the equivalent SDOF system and the target spectral displacement $S_{d t}{ }^{*}=D_{t}{ }^{*} /\left(\Gamma \phi^{T}\right)$ are determined.

According to the capacity spectrum method, the demand spectrum is obtained reducing the $5 \%$ damping response spectrum by multiplying for the damping correction factor $h$ that is function of $v_{t o t}$.

$$
\eta=\sqrt{\frac{10}{5+v_{t o t} \cdot 100}}=\frac{S_{v_{e f f}}}{S_{5 \%}}
$$

From Eq. (11), one obtain $v_{\text {tot }}^{*}$ the damping needed to reduce displacement up to the target $S_{d t}{ }^{*}$.

$$
v_{t o t}^{*}=0.1\left(\frac{S_{5 \%}}{S_{d t}^{*}}\right)^{2}-0.05
$$

(7) Evaluate the equivalent viscous damping contribution due to the naked structure: The contribute to damping of the structure $v_{e q, S}^{*}\left(D_{t}^{*}\right)$ can be determined from Eq. (9) being $D_{t}{ }^{*}$ the top displacement corresponding to $E_{D, S}^{\text {bilinear }}$ and $E_{S, S+B}$ that are the energy dissipated by $S$ and the elastic strain energy of
$S+B\left(E_{D, S}^{\text {bilinear }}\right.$ and $E_{S, S+B}$ are determined from the capacity curve of $S$ and $S+B$, respectively);

(8) Evaluate the additional equivalent viscous damping contribution due to braces: Given $v_{\text {tot }}^{*}$ from Eq. (12) the equivalent viscous damping needed to be supplied by the braces $v_{e q, B}^{*}\left(D_{t}^{*}\right)$ is evaluated as follows:

$$
v_{e q, B}^{*}\left(D_{t}^{*}\right)=v_{t o t}^{*}\left(D_{t}^{*}\right)-v_{e q, S}^{*}\left(D_{t}^{*}\right)-v_{I}
$$

(9) Dimensioning of the braces: Once the required equivalent viscous damping $v_{e q, B}^{*}\left(D_{t}^{*}\right)$ has been evaluated from Eq. (13), axial stiffness and yield strength required to achieve the desired additional damping can be determined with the same procedure previously adopted for the structure (Step 7).

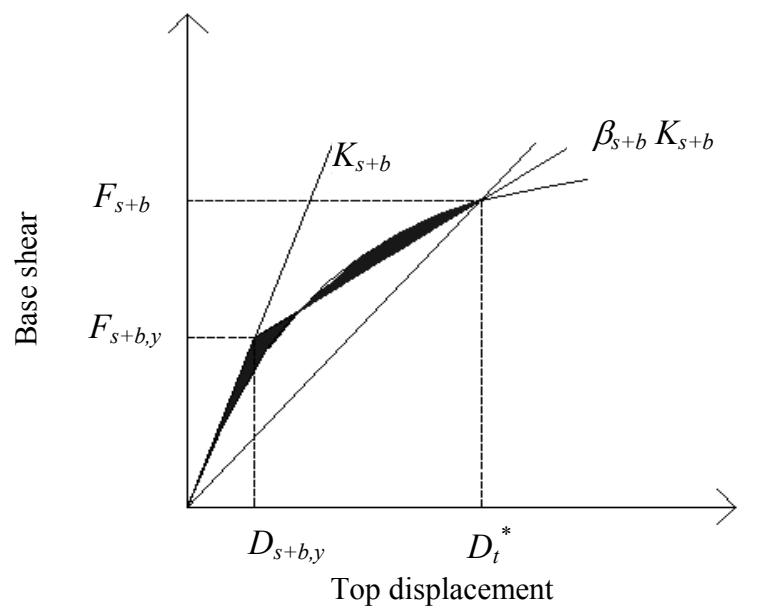

Fig. 1 Evaluation of the equivalent bilinear capacity curve.

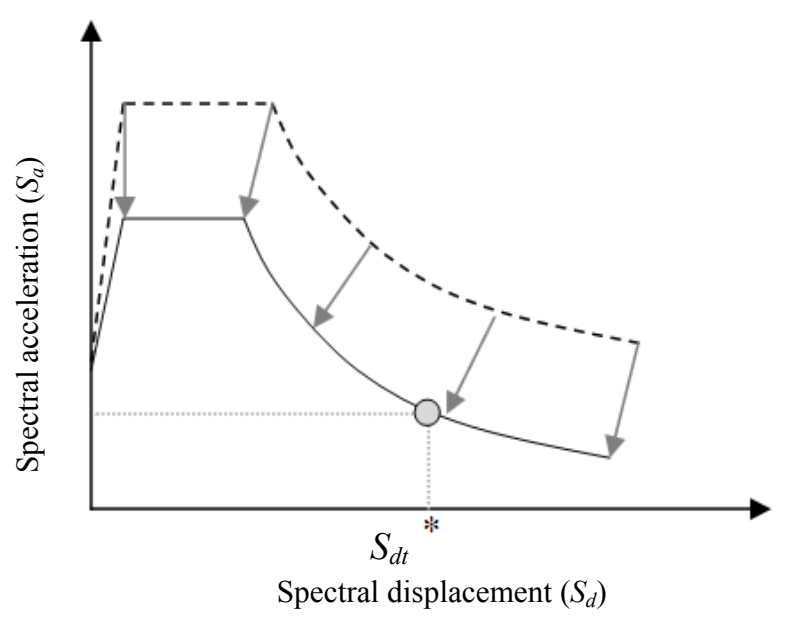

Fig. 2 Evaluation of the equivalent viscous damping needed to achieve the target performance point. 
The energy dissipated by the braces inserted at each $j_{\text {th }}$ level can be expressed as:

$$
E_{D, B}^{\text {bilinear }}=\sum_{j=1}^{n} 4\left(F_{b y}^{\prime} \delta_{j}^{\prime}-\delta_{y, j}^{\prime} F_{b, j}^{\prime}\left(\delta_{j}^{\prime}\right)\right)
$$

$\delta_{j}^{\prime}$ is the component of the interstory drift $\delta_{j}$ at $j_{t h}$ of the $n$ floors along the axe of the brace $\left(\delta_{y, j}^{\prime}\right.$ is the axial displacement corresponding to yielding of the device).

The axial displacement of the damping brace at the j th-floor $\delta_{b j}^{\prime}$ can be determined from its inclination angle $\theta_{b, j}$ and interstorey drift $\delta_{j}=D_{j}-D_{j-1}$ : therefore $\delta_{b, j}^{\prime}=\delta_{j} \cos \theta_{b j}$

The dissipative brace is usually constituted by a dissipative device (e.g., the $B R B$ ) assembled in series with an extension element (e.g., realized with a steel profile) in order to connect the opposite corners of a frame (Fig. 3).

Therefore, $K_{b, j}^{\prime}$ and $K_{b y, j}^{\prime}$ are the equivalent stiffness of the spring series in the elastic and plastic range respectively. $a=K_{p, j}{ }^{\prime} / K_{d, j}{ }^{\prime}$ is the ratio between elastic stiffness of the steel profile and of the device and $\beta_{d, j}$ the ratio between stiffness after and before yielding of the dissipative device, the following expression can be derived:

$$
K_{b, j}^{\prime}=\frac{K_{d, j}^{\prime}}{\frac{1}{\alpha_{j}}+1} ; K_{b y, j}^{\prime}=\frac{\beta_{b, j} K_{d, j}^{\prime}}{\frac{\beta_{b, j}}{\alpha_{j}}+1} ; \alpha_{j}=\frac{K_{p, j}^{\prime}}{K_{d, j}^{\prime}}(15)
$$

Therefore:

$$
\begin{gathered}
F_{b, j}^{\prime}=F_{b y, j}^{\prime}+\left(\delta_{j}^{\prime}-\delta_{y, j}^{\prime}\right) \frac{\beta_{b, j} K_{d, j}^{\prime}}{\frac{\beta_{b, j}}{\alpha_{j}}+1} \\
\delta_{y, j}^{\prime}=\frac{F_{b y, j}^{\prime}}{K_{b, j}^{\prime}}=\frac{F_{b y, j}^{\prime}}{K_{d, j}^{\prime}}\left(\frac{1}{\alpha_{j}}+1\right)
\end{gathered}
$$

Consequently, if there is one brace per direction and per floor, substituting Eq. (16) into Eq. (14), $v_{e q, B}^{*}\left(D_{t}^{*}\right)$ can be expressed in the following way:

$$
v_{e q, B}^{*}\left(D_{t}^{*}\right)=\chi_{B} \frac{2}{\pi} \frac{\sum_{j=1}^{n}\left\{F_{b y, j}^{\prime} \delta_{j}^{\prime}-\delta_{y, j}^{\prime} \cdot\left[F_{b y, j}^{\prime}+\left(\delta_{j}^{\prime}-\delta_{y, j}^{\prime}\right) \frac{\beta_{d, j} K_{d, j}^{\prime}}{\frac{\beta_{d, j}}{\alpha_{j}}+1}\right]\right\}}{F_{S, S+B}\left(D_{t}^{*}\right) \cdot D_{S, S+B}^{*}}
$$

where, $\delta_{j}{ }_{j}$ is determined from the pushover analysis for the top displacement $D_{t}$ and $\delta_{y, j}^{\prime}$, that is the yield displacement of devices, can be reasonable assumed as $\delta_{y, j}^{\prime} \leq \delta_{j}^{\prime} / 4$.

$F_{y, j}^{\prime}$ is the yielding force of the floor brace for each direction: once $\delta_{y, j}^{\prime}$ has been defined, $F_{y, j}^{\prime}$ is consequently determined Eq. (17). Thus, according to Eq. (15), $K_{d, j}^{\prime}$ can be expressed as follows:

$$
K_{d, j}^{\prime}=K_{\text {global }} \cdot c_{b, j} \cdot\left(\frac{1}{\alpha_{j}}+1\right)
$$

Therefore, substituting Eq. (19) into Eq. (18), $K_{\text {global }}$ can be determined as follows:

$$
K_{\text {global }}=\frac{\pi \cdot v_{e q, B}^{*}\left(D_{t}^{*}\right) \cdot F_{S, S+B}\left(D_{t}^{*}\right) \cdot D_{S, S+B}^{*}}{2 \cdot \chi_{B} \cdot C_{1}}
$$

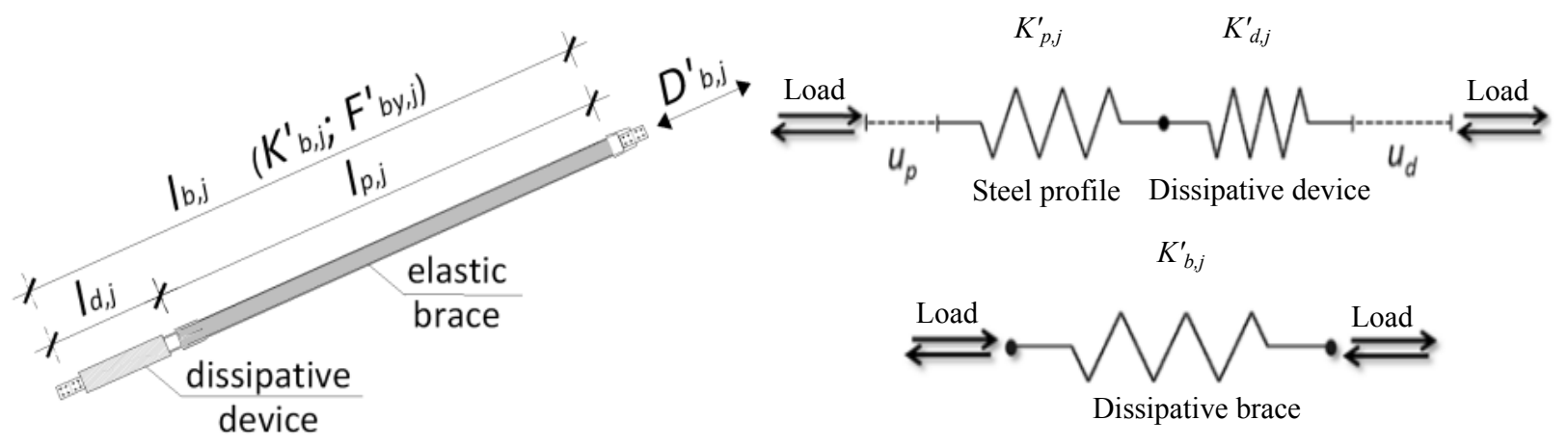

Fig. 3 Dissipative device " $j$ " assembled in series with an extension element (e.g., a steel profile): equivalent model of springs in series $\left(K_{d, j}^{\prime} ; K_{p, j}^{\prime}\right)$ and equivalent single spring model $\left(K_{b, j}^{\prime}\right)$. 
where,

$$
C_{1}=\sum_{j=1}^{n} c_{b, j}\left\{\delta_{y, j}^{\prime} \cdot \delta_{j}^{\prime}-\delta_{y, j}^{\prime}\left[\delta_{y, j}^{\prime}+\left(\delta_{j}^{\prime}-\delta_{y, j}^{\prime}\right) \frac{\beta_{b, j}\left(\frac{1}{\alpha_{j}}+1\right)}{\frac{\beta_{b, j}}{\alpha_{j}}+1}\right]\right\}
$$

A value of $a_{j}>3$ is usual in applications, therefore $K_{b, j}^{\prime}>3 / 4 K_{d, j}^{\prime}$. While the steel profile must be stronger (neither yielding nor buckling) than the device: for a given interstorey drift, the $a_{j}$ is larger, device displacements and hysteretic cycles are larger. At this point all terms of Eq. (20) are known from Eq. (19) and Eq. (15), the floor brace stiffnesses $K_{b, j}^{\prime}$ can be defined (the yield force $F_{b y, j}^{\prime}$ can be directly derived since the stiffness $K_{b, j}^{\prime}$ and the yield displacement $\delta_{y, j}^{\prime}$ have been defined). Though in this paper the procedure is discussed referring to Eq. (18), it is important to underline that, in a general case, the designer should have $m$ different braces for each level $j$. In fact, at the same level, each brace $I$ can be characterized by its specific properties as a consequence, for example, of the geometry of the bays of the structural frame. Consequently, Eq. (18) can be generalized as Eq. (22).

(10) Check convergence: the designer of the bracing system must repeat steps from three to nine until the PP (performance point) of the braced structure converges to the target displacement with adequate accuracy.

\section{Application on an Existing Build}

It is well known that results from a nonlinear static analysis are influenced by: pushover loading profile, characteristics of the numerical models. The loading profile determines load distribution and deformed shape of the building and, consequently, the plastic distribution of forces and displacements (interstorey drift can be strongly influenced). The most common loading profiles are: proportional to masses, proportional to first mode shape (monomodal), proportional to acceleration, multimodal. The procedure presented in the previous chapter is generally applied using a "standard" monomodal pushover, that is, the structure is subjected to monotonically increasing lateral forces, with an invariant spatial distribution (fundamental mode based), until collapse displacement is reached. This fundamental mode based force distribution does not account for higher mode contribution, which can be relevant, and therefore this limits the applicability of this approach to cases where the fundamental mode is dominant. Anyway it has to be highlighted that braces, if well designed, regularize the structure that can become strongly fundamental mode dependent. As discussed in the following with a specific case study, the use of the simple monomodal approach can be considered efficient. Therefore the proposed design procedure has been applied to retrofit an existing RC frame structure (Figs. 4 and 5) designed to resist vertical loads only: it is a strategic building that has been designed and built in the 1970s without seismic details, situated in a seismic area of Italy.

For brevity, in this paper, only results from longitudinal analysis are described. The design process has been performed considering the real 3D structure.

The procedure has been applied in order to retrofit the building referring to a seismic action evaluated using the technical code currently in force in Italy p.g.a. (peak ground acceleration) $0.25 \mathrm{~g}$; return period 949 years). The capacity curve has been derived considering a loading profile proportional to the first mode shape. In addition both the existing structure and

$$
v_{e q, B}^{*}\left(D_{t}^{*}\right)=\frac{2}{\pi} \frac{\sum_{j=1}^{n} \sum_{i=1}^{m} \chi_{B, i}\left\{F_{b y, j, i}^{\prime} \delta_{j}^{\prime}-\delta_{y, j, i}^{\prime} \cdot\left[F_{b y, j, i}^{\prime}+\left(\delta_{j}^{\prime}-\delta_{y, j, i}^{\prime}\right) \frac{\beta_{d, j, i} K_{d, j, i}^{\prime}}{\frac{\beta_{d, j, i}}{\alpha_{j, i}}+1}\right]\right\}}{F_{S, S+B}\left(D_{t}^{*}\right) \cdot D_{S, S+B}^{*}}
$$




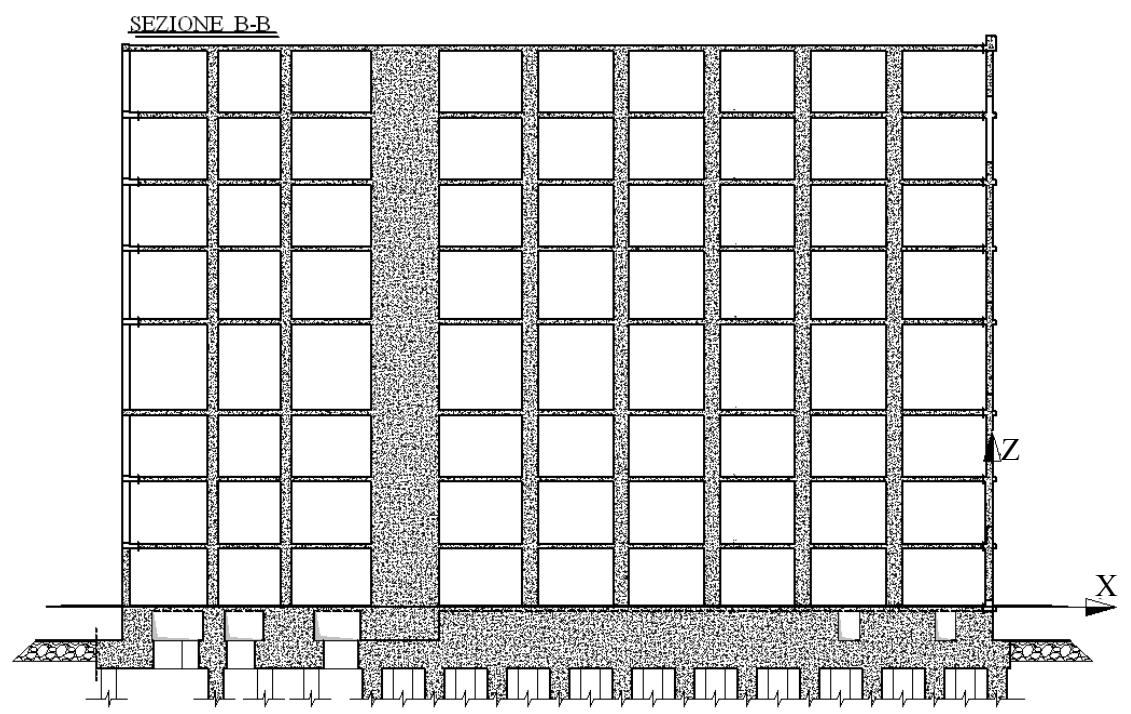

Fig. 4 Longitudinal sections of the building.

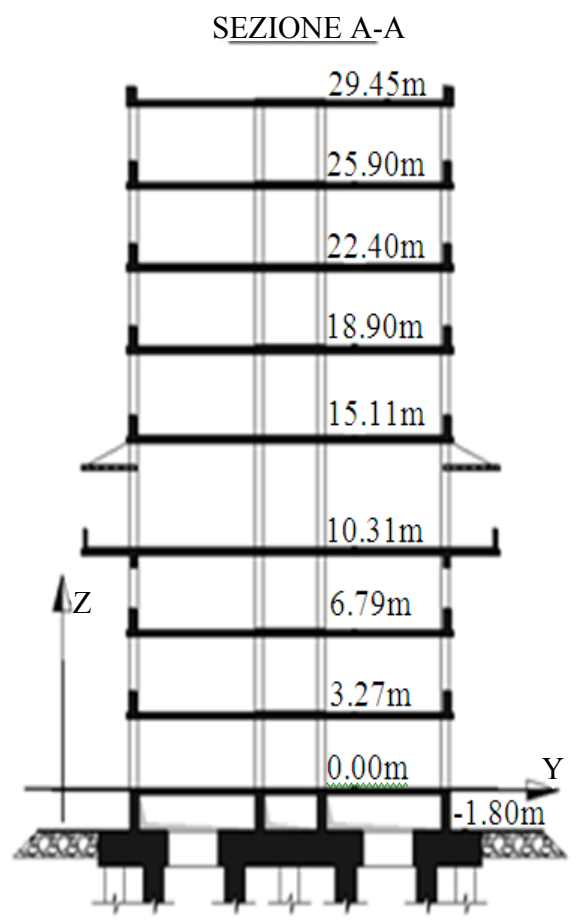

Fig. 5 Transverse section of the building.

the retrofitted structure have been studied using the multimodal pushover [3] in order to evaluate the effectiveness of the "standard" procedure and therefore the advantages on using the monomodal pushover for such a building. In this case, the effectiveness of the procedure has been confirmed, and comparing results from monomodal and multimodal pushover applied on the retrofitted structure, the use of multimodal pushover can be considered not substantial for the design process applied on this typology of building. The performance point of the existing structure in terms of base shear and top displacement is $V_{S}=9,908$ $\mathrm{kN}$ and $D_{t, S}=133 \mathrm{~mm}$. Then, the selected performance objective was to reduce displacement in order to avoid damage on both RC elements and masonry panels. Therefore the target displacement has been selected adopting the following parameters: reducing the top displacement of about $50 \%\left(D_{t, \text { Starg }}=66 \mathrm{~mm}\right)$ and limiting the interstorey drift to $2 \%$ at whichever level. Convergence to the desired values has been obtained with three iterations and the final results (performance point, iteration 3)are the base shear $V_{S+B}=12,105 \mathrm{kN}$, with a $19 \%$ increase with respect to the original building, and the top displacement $D_{t, S+B}=61 \mathrm{~mm}$ (practically coincident with the target, see Fig. 6).

The contribution to dissipation (Fig. 7) offered by the dissipative system is $v_{e q B}=20 \%\left(v_{e q S}=12 \%, v_{I}=\right.$ $5 \%$ ). In the final configuration the interstorey drift of each level has been significantly reduced to values lower than $2 \%$ and all the dissipative braces are in their plastic range (Fig. 8). Based on the distribution of interorey drift, the braced structure is strongly characterized by a prevalent first mode and consequently the multimodal analysis can be considered unnecessary: the two approaches differ of less than $1.5 \%$ (Fig. 9). 


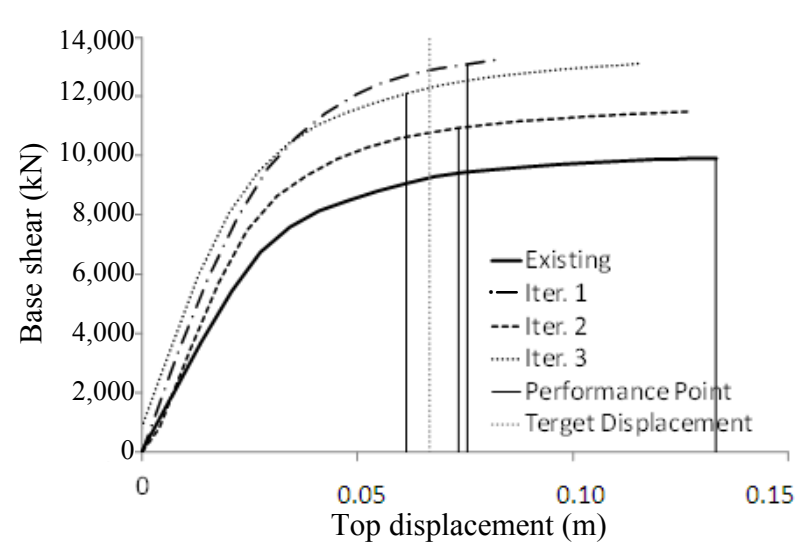

Fig. 6 Capacity curves from pushover analysis along the longitudinal direction (Existing structure and braced structure at each iter from 1 to 3 ).

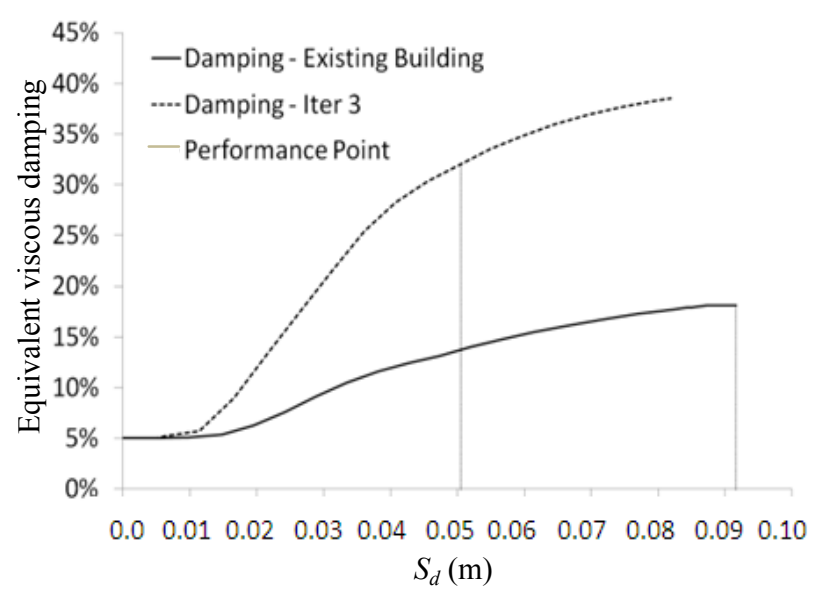

Fig. 7 Variation of the total equivalent viscous damping with the spectral displacement $S_{d \cdot}$. At the PP $v_{e q, S+B}=32 \%$ for the retrofitted structure and $v_{e q, S}=14 \%$ for the existing building.

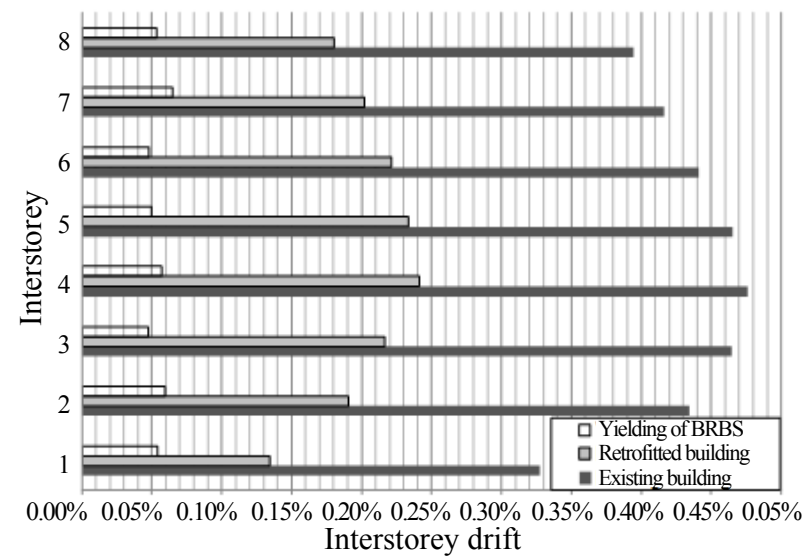

Fig. 8 Interstorey drift (longitudinal) distribution for the existing building and the retrofitted building (longitudinal direction). In the graph, it is also indicated the drift corresponding to the yielding of the BRBs.

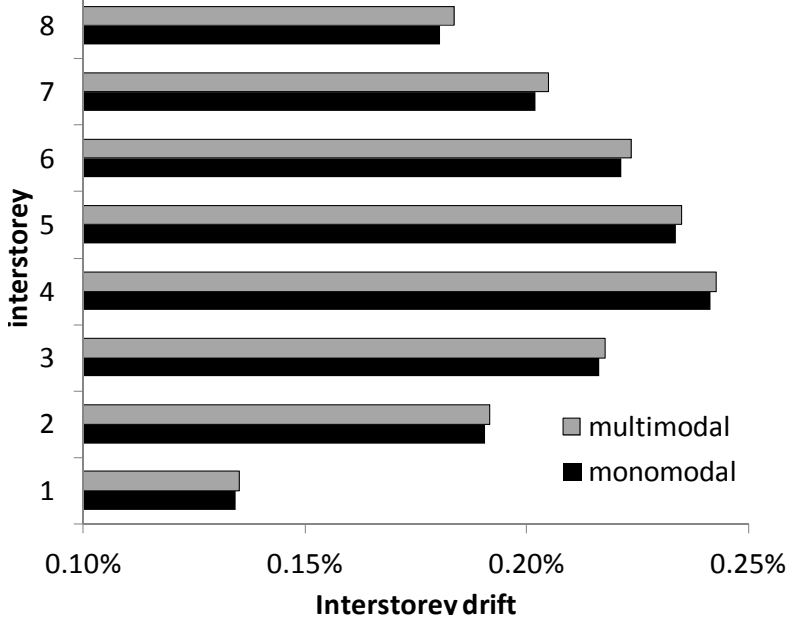

Fig. 9 Interstorey drift (longitudinal) distribution in the retrofitted building obtained using the monomodal and the multimodal pushover. Differences are lower than $1.5 \%$.

\section{Conclusions}

A procedure for design of retrofitting of building structures using dissipative braces has been presented. The procedure, that in previous works has been applied to retrofit building up to four stories $[1,2]$ has been updated with the use of the multimodal pushover and successfully applied to a structure having eight floors (30 $\mathrm{m}$ height). The target displacement has been determined, both in longitudinal and transverse direction, for limiting both interstory drifts and ductility demand on existing structural elements. The final configuration obtained (the building braced along both the directions) has been tested by performing pushover analyses proportional to the most relevant mode shapes (along both the longitudinal and transverse direction) of the building fully braced. Afterwards, results obtained from the monomodal pushover analysis have been compared with results from multimodal pushover analysis. First, the application proves the effectiveness of the procedure. Moreover, from this comparison, it has been observed that, in terms of drifts and displacements, the multimodal pushover can be considered not relevant for the design procedure for dissipative braces proposed by Bergami and Nuti [1, 2], if multimodal pushover is applied on structures such as the midrise 
$\mathrm{RC}$ frame building.

\section{References}

[1] A.V. Bergami, C. Nuti, A design procedure of dissipative braces for seismic upgrating structures, Earthquakes and Structures 4 (1) (2013) 85-108.

[2] A.V. Bergami, C. Nuti, Seismic retrofit of RC structures with dissipative braces, design and sustainability, in: FIB Symposium 2011, Prague, Czech Republic, 2011.
[3] A.K. Chopra, R.K. Goel, Modal pushover analysis procedure for estimating seismic demands for buildings, Earthquake Engineering and Structural Dynamics 31 (3) (2002) 561-582.

[4] Seismic Evaluation and Retrofit of Concrete Buildings, Report ATC-40, Applied Technology Council, Redwood City, California, 1996.

[5] SEAOC/AISC, Recommended Provisions for Buckling-Restrained Braced Frames, Structural Engineering Association of California/American Inst. of Steel Const., 2005. 